\title{
Global high-resolution reference potential evaporation
}

\author{
F.C. Sperna Weiland ${ }^{\text {a }}$ P. Lopez ${ }^{\text {a,b }}$, A.I.J.M. van Dijk ${ }^{\mathrm{c}}$ and $\underline{\text { J. Schellekens }}^{\text {a }}$ \\ ${ }^{a}$ Deltares, Delft, The Netherlands, ${ }^{b}$ Utrecht University, Utrecht, The Netherlands, ${ }^{c}$ Australian National \\ University, Australia \\ Email: Jaap.Schellekens@deltares.nl
}

\begin{abstract}
The increasing pressure on water resources worldwide request for both global and local scale assessments of fresh water availability. Gridded global reference potential evaporation (PET) datasets derived from either satellite or re-analysis data already exist, yet their time-coverage is often limited. Moreover the spatial and/or temporal resolution does not match the local scale requirements or the ever increasing resolutions of global hydrological models. We here introduce a high-resolution gridded reference potential evaporation dataset covering a period of 34 years that can be used in data sparse regions and for global scale analysis.
\end{abstract}

The dataset is derived from the WATCH-Forcing-Data-ERA-Interim (WFDEI) dataset which has a resolution of $0.5^{\circ}$ by $0.5^{\circ}$. By basic oversampling of such coarse data large and systematic biases are introduced, particularly in areas with strong relief. By down-scaling based upon a high resolution DEM, the main variables for determining reference evaporation can be down-scaled and improved considerably for the complete period of the reanalysis based meteorological forcing.

Down-scaling 10x10 km resolution was performed by applying a lapse rate on temperature, an altitude correction on air pressure and incoming radiation and by taking the effect of aspect, slope and local shading on illumination into account. Subsequently we produced Penman-Monteith, Priestley-Taylor and Hargreaves reference evaporation estimates. We analysed the impact of the down-scaling methods on calculated reference evaporation by comparison with (1) reference potential evaporation estimates based upon the WorldClim datasets and (2) locally derived Hargreaves evaporation for the Australian Murrumbidgee basin.

The WFDEI based Hargreaves estimates show highest resemblance with the WorldClim estimates, the Priestley-Taylor estimates are closest to the ensemble mean of the three estimates. The Penman-Monteith equation results in relatively large biases for the Sahara, Amazon and desert region of Australia. This is in line with other comparisons of the different PET equations for arid climates.

The high resolution data and the down-scaling tools are made available through the eartH2Observe data portal at http://wci.earth2observe.eu and https://github.com/earth2observe/downscaling-tools.

Keywords: Reference potential evaporation, eartH2Observe, WFDEI, high-resolution 


\section{INTRODUCTION}

Available global water resources are under pressure due to the increasing world population and the local impacts of climate change (Faures, 2006; McDonald et al., 2011). Water resources assessments can help us to better understand the natural variability, the impact of water uses, and to detect possible trends. The current study is part of the EU FP7 project eartH2Observe (www.earth2observe.eu) that focusses on the construction of a global meteorological and hydrological re-analysis dataset to be used for local scale water resources assessments worldwide. The contribution of evaporation to the water balance is often assessed by using reference potential evaporation as forcing for a hydrological model (Oudin et al., 2005). To this end timeseries of global gridded reference potential evaporation - that can be converted to a potential evapotranspiration that is consistent with the surface representation in a local scale hydrological model using crop factors - could be of great value.

In previous work we estimated reference potential evaporation from the CFSR re-analysis dataset (Sperna Weiland et al., 2012) using four different equations - Penman-Monteith (PM), Priestley-Taylor (PT), Hargreaves $(\mathrm{HG})$ and Blaney-Criddle $(\mathrm{BC})$ at a resolution of $0.5^{\circ}$ by $0.5^{\circ}$. From the evaluation of products it was concluded that an empirical temperature based equation like $\mathrm{HG}$ performs similar to the physically based PM equation. This conclusion was also drawn by Droogers and Allen (2002). Recently Trambauer et al. (2014) evaluated ERA-Interim reanalysis (Dee et al., 2011) based HG and PM potential and actual evaporation estimates over the African continent and created an improved Actual Evaporation Multiproduct at a $0.5^{\circ}$ resolution.

The above datasets are available at a resolution of $0.5^{\circ}$ by $0.5^{\circ}$, whereas both for local scale applications and for global hydrological models that are being run with ever increasing resolutions, higher resolution data could significantly improve discharge simulations. Additional processing is needed to downscale the data. By using a high resolution DEM, the main variables for determining reference evaporation can already be downscaled and improved considerably.

We apply three equations; FAO PM, PT and HG. All equations are developed to calculate reference potential evaporation - i.e. the evaporative demand of a well-watered hypothetical grass reference crop. We derive the global reference potential evaporation fields from down-scaled WDFEI (Weedon et.al., 2014) reanalysis data at a $5 \mathrm{~min}$ resolution (approximately $10 \times 10 \mathrm{~km}$ ). The reference potential evaporation estimates are globally compared with estimates based upon the WorlClim dataset (Hijmans et al., 2005) and locally verified for the Murrumbidgee catchment, Australia.

\section{DATA AND METHODS}

\subsection{Data}

\section{WFDEI dataset}

Within the EU FP6 WATCH project (Harding et al., 2011) a global meteorological forcing dataset was created that covers the period 1901-2001. It was constructed by optimizing the ERA-40 re-analysis dataset (Uppala et al., 2005) with in-situ meteorological measurements from global gridded datasets. More recently this dataset has been extended to the year 2012 using the same optimization method in combination with the ERA-Interim re-analysis dataset (WFDEI; Weedon et al., 2014). The WFDEI dataset covers the period 1979 to 2012 and has a horizontal resolution of $0.5^{\circ}$ by $0.5^{\circ}$. It contains all variables required to estimate reference potential evaporation with the three equations of interest.

\section{WorldClim}

The reference potential evaporation estimates are evaluated against the Global Potential EvapoTranspiration dataset (Global-PET: Zomer et al., 2007) provided by the Consultative Group for International Agricultural Research (CGIAR) which is derived from the WorldClim dataset (Hijmans et al., 2005). We used the monthly climatology that is representative for the period 1950-2000 and available at a resolution of 30 arc seconds. This climatology is derived from monthly PET time-series that are calculated with the HG equation from the WorldClim dataset and extra-terrestrial radiation fields. Unfortunately the WorldClim is representative for a period further back in time. We assume that between 1951-2000 and 1979-2010 the order of magnitude has not change much and at least the direction of the biases between the datasets should have remained representative. 


\section{Australian data}

For the evaluation in the Murrumbidgee basin we use HG reference evaporation derived from a Australian local high resolution gauging station based gridded datasets $\left(0.05^{\circ}\right)$ sourced from the Australian Bureau of Meteorology (Jones et al., 2009).

\subsection{Methods}

\section{Three approaches for estimating reference potential evaporation}

The $\boldsymbol{P M}$ equation is a physically based equation considering most relevant atmospheric processes. It can be used to derive reference potential evapotranspiration using the FAO parameterisation (Allen et al., 1998) yet it is known to be affected by site specific aridity (Trambauer et al, 2014).

The $\boldsymbol{H G}$ equation is a simplified from of the PM equation (Hargreaves and Samani, 1985). The influence of humidity is approximated with the diurnal temperature range and radiation is defined by an annual average extraterrestrial radiation cycle. By the introduction of empirical relations it could be less responsive to spatial and temporal climate variability (Droogers and Allen, 2002).

The $\boldsymbol{P T}$ equation is a substitute of the PM equation where the aerodynamic term has been replaced by an empirical multiplier $-\alpha$ - to make the equation less data demanding. Yet, it still considers the temporal variation in radiation as well as temperature. Several studies reported the underestimation of evaporative demand in arid regions by the PT equation (Weiss and Menzel, 2008; Maidment, 1992). We follow Maidment (1992) and increase the empirical multiplier for arid regions from 1.26 to 1.74 . We define arid regions based upon the climate moisture indices of the WWDRII (UN, 2006).

\section{Spatial down-scaling}

Down-scaling is based on a high-resolution DEM derived from the Shuttle Radar Topography Mission at 90m resolution (SRTM-90). For temperature a lapse rate of 0.6 degree Kelvin per $100 \mathrm{~m}$ was applied. For air pressure an altitude correction was made following the hydrostatic pressure equation. Down-scaling and correction of incoming radiation was based on the effect of aspect, slope and local shading on illumination using three steps. (1) Clear sky radiation perpendicular to the radiation beam was estimated for each cell using monthly linke turbidity maps (Remund et. al. 2003). (2) Clear sky radiation converted to a horizontal surface was compared to the re-analysis based radiation and used to derive a clear sky index kc (c.f. Beyer et. al. 1996) that can be used to estimate the direct and diffuse components of the radiation. (3) Direct radiation was corrected for altitude, aspect, slope and shading taking into account the differences between the original $\left(0.5^{\circ} \times 0.5^{\circ}\right)$ digital elevation model (DEM) and the high resolution DEM, while diffuse radiation was corrected for altitude differences only.

\section{RESULTS}

\subsection{Map comparison of methods}

The maps in Figure 3.1 show long term average daily evaporation ( $\mathrm{mm} /$ day). Highest values are found for the PM equations for the Sahara and Australian desert, whereas the PM method results in relatively low values in the tropical Amazon and Mid-West Africa. The HG method gives relatively high values for the Amazon and Mid-West Africa. PT reference PET is relatively low and shows highest agreement with the HG method. The major differences between the three methods can be found in the deserts in these arid regions differences between the PM and simplified methods, such as the HG and PT equations in which parameters are often locally adjusted, are known to be significant (c.f. Tabari and Talaee, 2011; Trambauer et al, 2014; Weiss and Menzel, 2008). 

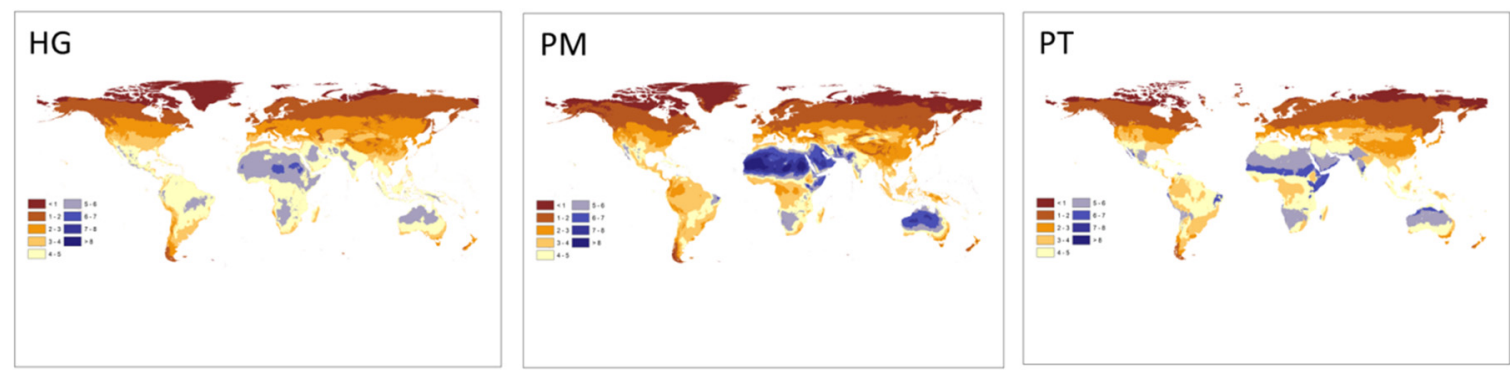

Figure 3.1. long-term average daily reference evaporation ( $\mathrm{mm} /$ day) with from left to right $\mathrm{HG}$, PM and PT estimates.

\subsection{Evaluation with Hargreaves WorldClim}

HG reference potential evaporation derived from the WFDEI dataset shows small biases - mainly underestimations - from the WorldClim derived estimates (see Fig. 3.2). This is most likely a result of the use of the same equation that only depends on temperature for which biases are often small. Biases for the PM equation are again relatively large for the Sahara, Australian desert and the Amazonian basin. The PT results show underestimations for the Amazonian basin and Mid-West Africa and over estimations for Australia, yet biases are smaller here.
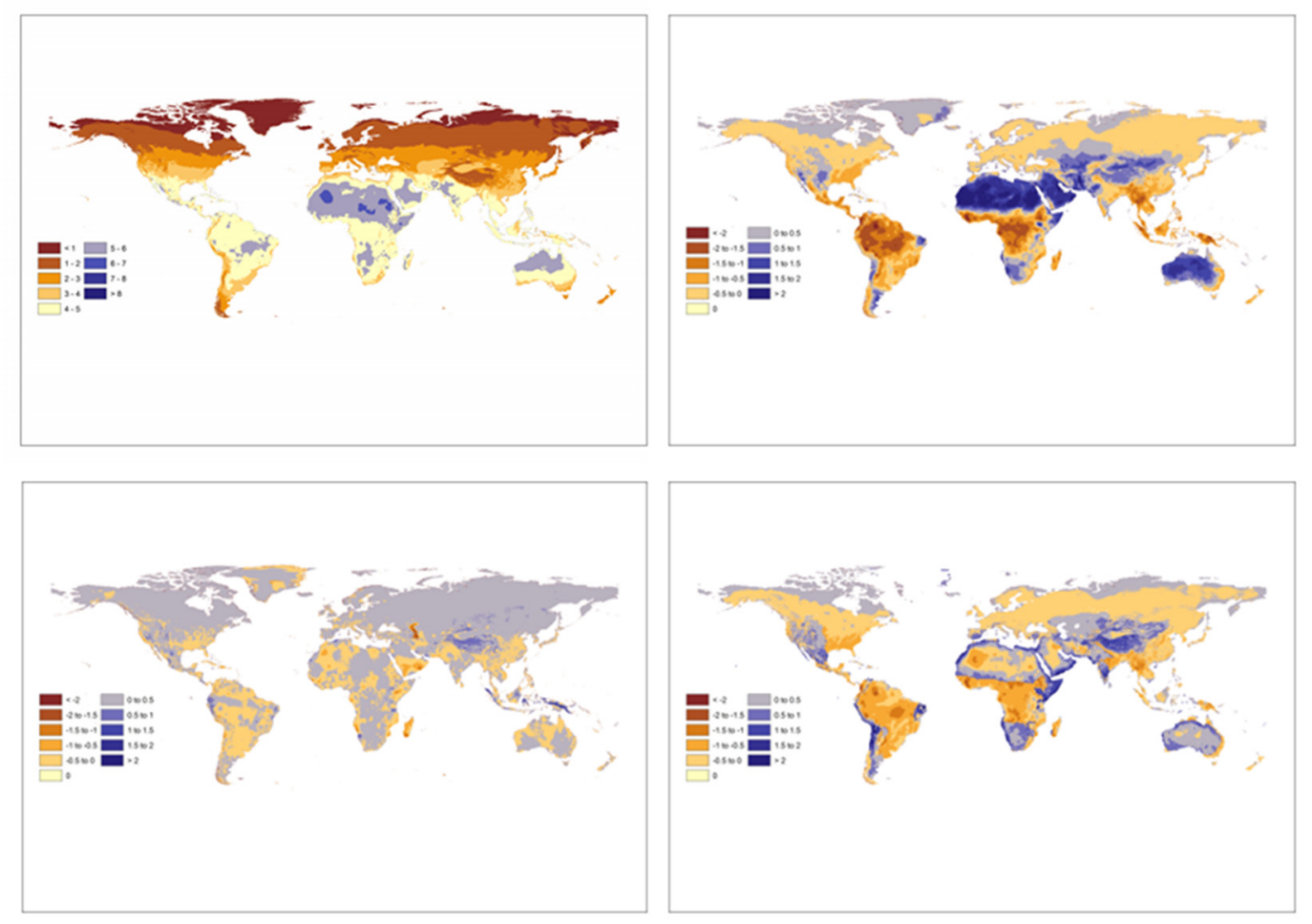

Figure 3.2. Top-left: HG reference potential evaporation derived from the WorldClim dataset (mm/day). Remaining maps: bias from the WorldClim estimate ( $\mathrm{mm} /$ day) for HG (bottom-left), PM (top-right) and PT (bottom-right).

\subsection{Comparison of time series per climate zone}

The results in Figure 3.2 indicate that the differences between the three methods vary between climate zones. Therefore, Figure 3.4 shows the average climatology (per day of the year) for a number of selected climate zones for the three methods. As can be seen differences are largest in Af, Aw and BWh zones and results are more comparable in Cfa, Cfb and Dfc. This confirms results by Tabari and Talaee, (2011) and Trambauer et al (2014) and suggest that for a global application some of the constants in the simplified methods should be adjusted in the more extreme climate zones. 

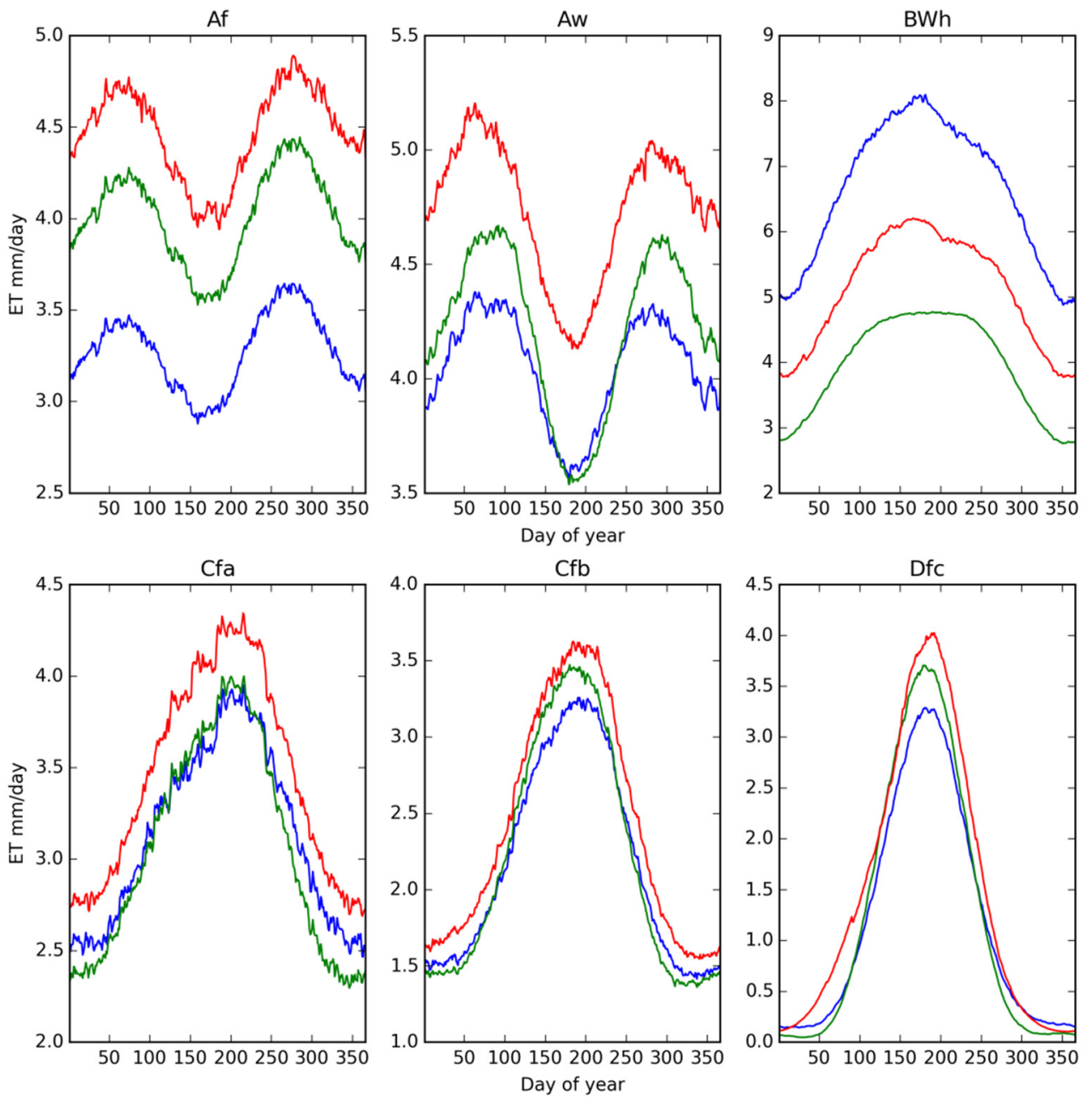

Figure 3.3. Climatology for a number of selected Köppen climate zones. Blue: PM, Green: PT and Red: HG

\subsection{Evaluation for the Murrumbidgee catchment}

The global potential evaporation estimates for the Murrumbidgee catchment resemble the local estimates quite well. The catchment maps with PM reference PET in Figure 3.4 show that DEM based down-scaling and radiation correction, introduce the level of detail that can also be reached when using local data. In addition the overestimates in the mountainous region (middle panel south-east) are reduced.
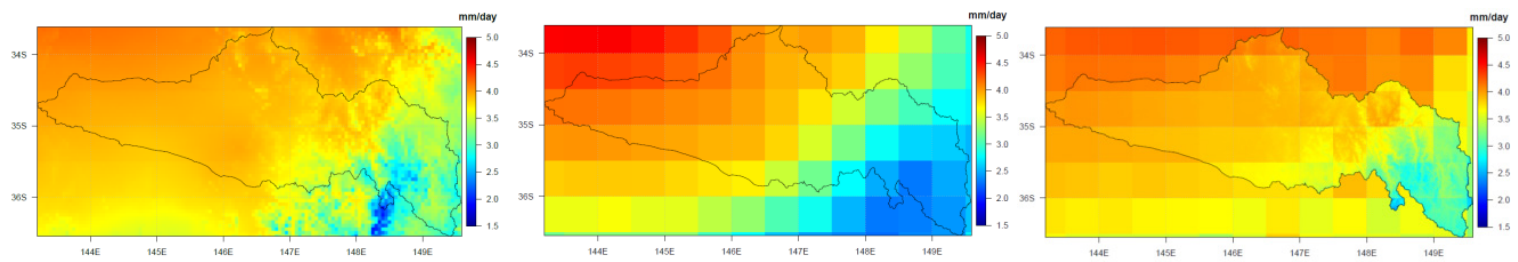

Figure 3.4. Long-term average reference evaporation ( $\mathrm{mm} /$ day) for the Murrumbidgee catchment for the period 19792010 calculated with the PM equation applied to the local dataset (left), the non down-scaled WFDEI dataset (middle) and down-scaled radiation corrected WFDEI dataset (right). 
We calculated basin average daily PM potential evaporation time-series derived from both the WFDEI and gridded Australian dataset - see Fig 3.5. ThePM and HG estimates show the highest agreement with locally derived values. The PT method underestimates the other estimates, differences are largest from March to August.

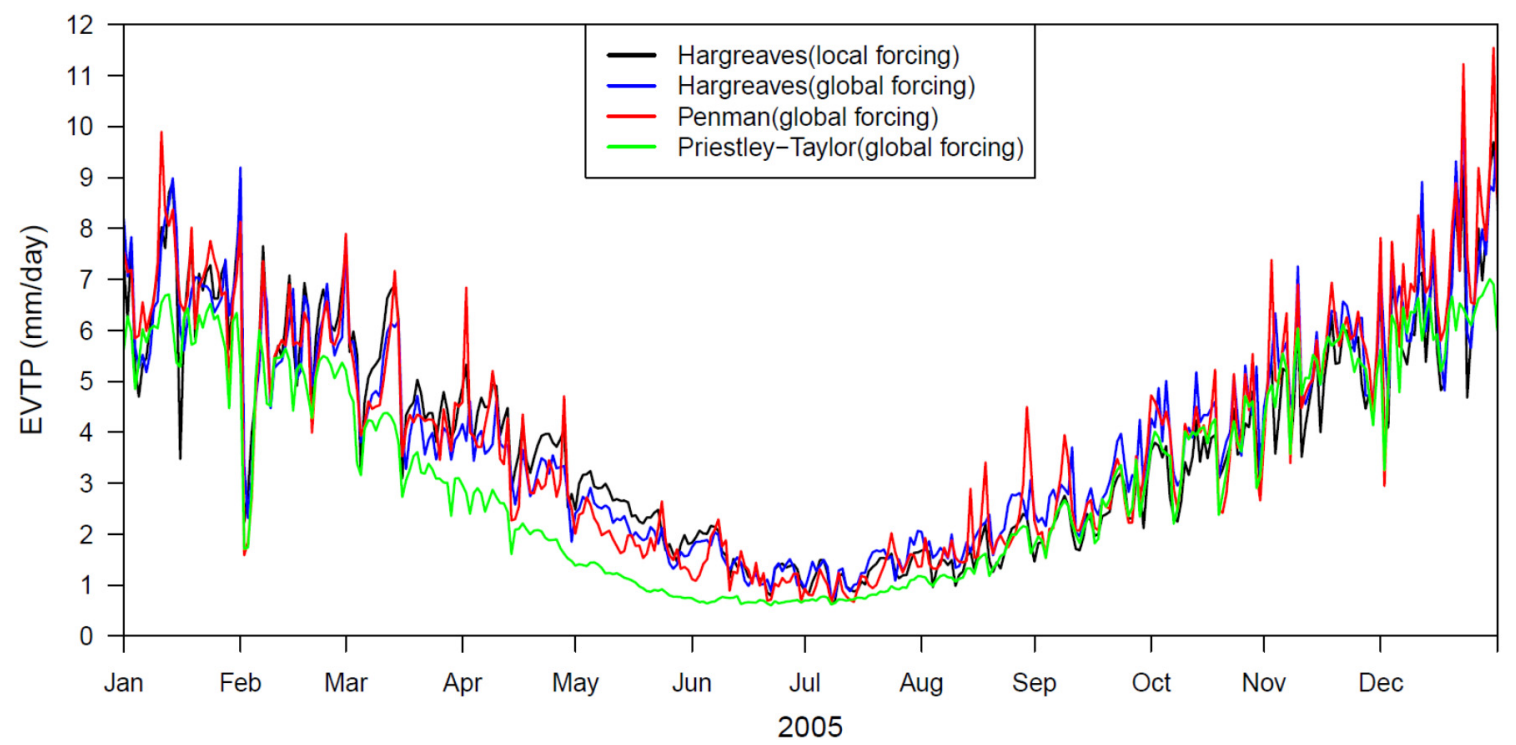

Figure 3.5. Time-series of daily reference global down-scaled evaporation estimates and the HG equation applied to the local high-resolution dataset.

Table 3.1. Correlation between daily reference evapo-ration time-series derived from the global dataset and reference Hargreaves evaporation derived from the local Australian dataset for Canberra airport.

\begin{tabular}{|l|l|l|l|}
\hline Correlation & PM & PT & HG \\
\hline $\mathbf{0 . 5}$ degrees & 0,9325 & 0,9259 & 0,9592 \\
\hline $\mathbf{1 ~ k m}$ & 0,9324 & 0,9258 & 0,9592 \\
\hline
\end{tabular}

\section{DISCUSSION AND CONCLUSION}

The presented reference potential evaporation estimates resemble the WorldClim dataset quite. Largest differences are found over the Saharas, Amazon and desert region of Australia. This suggests that the global results should be used with caution in the more extreme climate zones. Yet, the small differences between the WorldClim dataset and the downscaled HG estimates suggest the downscaling procedure works relatively well. Moreover, the results per climate zones suggest that the differences between the WordClim dataset and the present results originate from the three different equations.

At the local scale, the evaporation maps for the Murrumbidgee catchment illustrate the value of the additional level of detail introduced by downscaling and correcting the meteorological input data.

The final down-scaled HG and PM daily evaporation time series resemble local estimates quite well, which is a promising result for the use of this dataset for water resources assessments in data sparse regions.

\section{DATA AVAILABILITY}

The global reference potential evaporation estimates are available at the eartH2Observe data portal: https://wci.earth2observe.eu/ while the downscaling scripts are available at: https://github.com/earth2observe/downscaling-tools. These scripts can be used for local downscaling to higher resolutions.

\section{ACKNOWLEDGEMENTS}

This research received funding from the European Union Seventh Framework Programme (FP7/2007- 
2013) under grant agreement no. 603608, "Global Earth Observation for integrated water resource assessment": eartH2Observe.

\section{REFERENCES}

Allen et al. (1998).: Crop evapotranspiration-Guidelines for computing crop water requirements-FAO Irrigation and drainage paper 56, FAO, Rome, 300, 6541, http://www.engr.scu.edu/ emaurer/classes/ ceng140_watres/handouts/FAO_56_Evapotranspiration.pdf.

Beyer, H.G., Costanzo, C., Heinemann, D., 1996. Modifications of the Heliosat procedure for irradiance estimates from satellite images. Solar Energy 56, 207-212.

Dee et al. (2011). The ERA-Interim reanalysis: configuration and performance of the data assimilation system, Q. J. Roy. Meteorol. Soc., 137, 553- 597, doi:10.1002/qj.828.

Droogers, P. and Allen, R. G. (2002). Estimating reference evapotranspiration under inaccurate data conditions, Irrig. Drain. Syst., 16, 33-45.

Faures, J. M. (2006). Mapping Existing Global Systems \& Initiatives Background Document, prepared by FAO on behalf of the UN-Water Task Force on Monitoring Stockholm, 21 August 2006,.

Harding, R., Best, M., Blyth, E., Hagemann, S., Kabat., P., Tallaksen, L.M., Warnaars, T., Wiberg, D., Weedon, G.P., Van Lanen, H.A.J., Ludwig, F. and Haddeland, I. (2011). Preface to the "Water and Global Change (WATCH) special collection: Current knowledge of the terrestrial Global Water Cycle". J. of Hydrometeorology 12(6): 1149-1156, DOI: 10.1175/JHM-D-11-024.1.

Hargreaves, G.H. and Samani, Z.A. (1985). Reference crop evapotranspiration from temperature. Appl. Eng. Agric., 1, 96-99.

Hijmans, R.J., S.E. Cameron, J.L. Parra, P.G. Jones and Jarvis, A. (2005). Very high resolution interpolated climate surfaces for global land areas. International Journal of Climatology, 25, 1965-1978.

Jones, D.A., Wang, W. and Fawcett, R.J.B. (2009). High-quality spatial climate data-sets for Australia. Australian Meteorological and Oceanographic Journal. 58 233-248.

Maidment (1992). Handbook of hydrology, McGraw-Hill, New York.

McDonald, R.I., Green, P., Balk, D., Fekete, B.M., Revenga, C., Todd, M., and Montgomery, M. (2011). Urban growth, climate change, and freshwater availability, Proceedings of the National Academy of Sciences, 108, 6312-6317, http://www.pnas.org/content/108/15/6312.short.

$\mathrm{Mu}$, Q., Zhao, M., and Running, S. W. (2011). Improvements to a MODIS global terrestrial evapotranspiration algorithm, Remote Sens. Environ., 115, 1781-1800.

Oudin, L., Hervieu, F., Michel, C., Perrin, C., Andreassian, V., Anctil, F., and Loumagne, C. (2005). Which potential evapotranspiration input for a lumped rainfall-runoff model? Part 2 - Towards a simple and efficient potential evapotranspiration model for rainfall-runoff modeling. J. Hydrol., 303, 290-306, doi:10.1016/j.jhydrol.2004.08.026.

Remund, Jan, Lucien Wald, Mireille Lefevre, Thierry Ranchin, and John Page. (2003). Worldwide Linke Turbidity Information. In ISES Solar World Congress 2003, 400:13 - p. International Solar Energy Society (ISES).

Sperna Weiland, F. C., Tisseuil, C., Dürr, H. H., Vrac, M., and van Beek, L. P. H. (2012). Selecting the optimal method to calculate daily global reference potential evaporation from CFSR reanalysis data for application in a hydrological model study, Hydrol. Earth Syst. Sci., 16, 983-1000.

Tabari, H. and Talaee, P. (2011) Local Calibration of the Hargreaves and Priestley-Taylor Equations for Estimating Reference Evapotranspiration in Arid and Cold Climates of Iran Based on the PenmanMonteith Model. Journal of Hydrologic Engineering 16, 837-845. doi:10.1061/(ASCE)HE.19435584.0000366

Trambauer, P., Dutra, E., Maskey, S., Werner, M., Pappenberger, F., van Beek, L. P. H., and Uhlenbrook, S. (2014). Comparison of different evaporation estimates over the African continent, Hydrol. Earth Syst. Sci., 18, 193-212, doi:10.5194/hess-18-193-2014.

UN (2006). 2nd UN World Water Development Report: WWDRII data download page, http://wwdrii.sr.unh.edu/download.html (last access: August 6, 2015).

Uppala et al. (2005. The ERA-40 re-analysis. Q.J.R. Meteorol. Soc., 131: 2961-3012. doi: 10.1256/qj.04.176

Weedon, G.P., Balsamo, G., Bellouin, N., Gomes, S., Best, M.J. and Viterbo P. (2014). The WFDEI meteorological forcing data set: WATCH Forcing Data methodology applied to ERA-Interim reanalysis data. Water Resources Research, 50, 7505-7514, doi:10.1002/2014WR015638.

Weiss, M. and Menzel, L. (2008). A global comparison of four potential evapotranspiration equations and their relevance to stream flow modelling in semi-arid environments, Advances in Geosciences, 18, 15 - 23

Zomer, R.J., Trabucco, A., Van Straaten, O. and Bossio, D.A. (2007). Carbon, Land and Water: A Global Analysis of the Hydrologic Dimensions of Climate Change Mitigation through afforestation / Reforestation, Research Report 101, IWMI, Sri Lanka. 